\begin{tabular}{ccc}
\hline & $\begin{array}{c}\text { International Journal of Current Research in } \\
\text { Biosciences and Plant Biology } \\
\text { BXCELLENT } \\
\text { PUBLISHERS }\end{array}$ \\
Volume $4 \cdot$ Number 1 (January-2017) • ISSN: 2349-8080 (Online) \\
Journal homepage: www.ijcrbp.com
\end{tabular}

\title{
A Modified Protocol for Agrobacterium Mediated Transformation of Tomato Plants
}

\author{
Pranav Kumar Mishra ${ }^{1}$, H. P. Jai Shanker Pillai ${ }^{2}$, Herman Kopa ${ }^{2}$, Megha Gupta ${ }^{1}$ and \\ Selvam Arjunan ${ }^{2} *$
}

\author{
${ }^{I}$ Center for Research and PG studies, Department of Biotechnology, Indian Academy Degree College (Autonomous), Kalyan \\ Nagar, Bangalore, Karnataka-560 043, India \\ ${ }^{2}$ Center for Research and PG studies, Department of Life Sciences, Kristu Jayanti College (Autonomous), K. Narayanapura, \\ Kothanur (P.O), Bangalore, Karnataka-560 077, India
}

*Corresponding author.

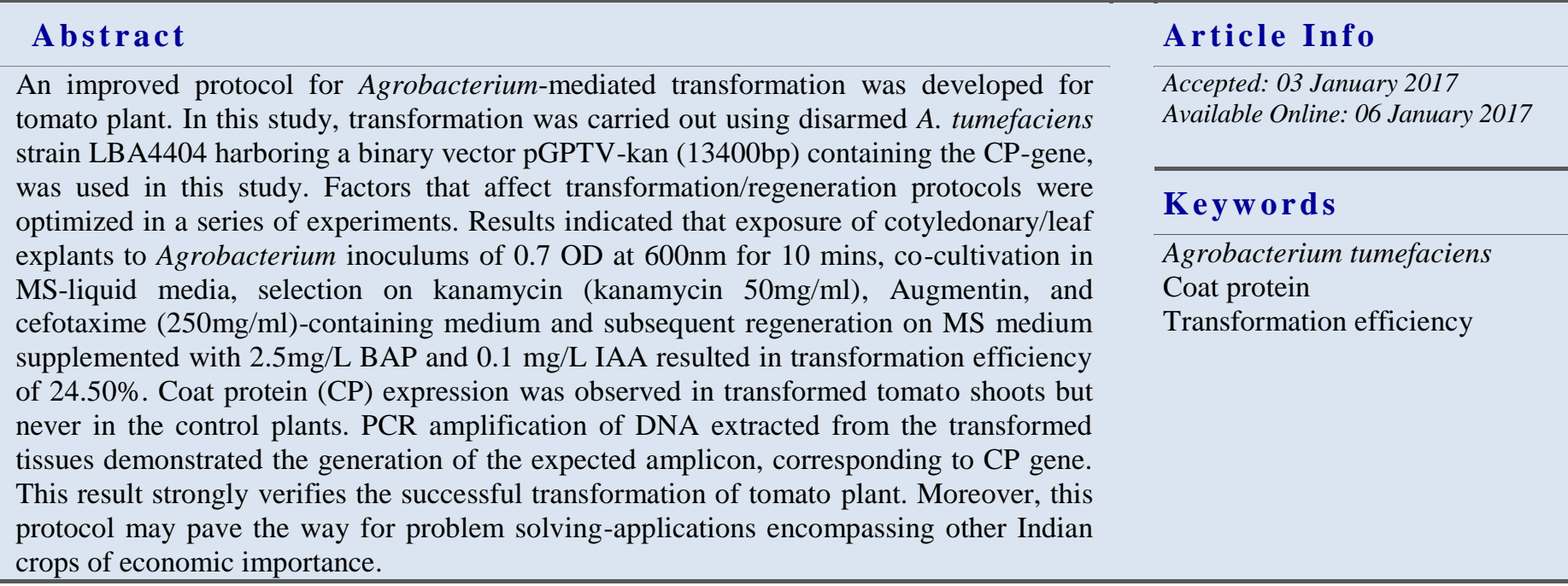

\section{Introduction}

Tomato (Lycopersicum esculentum Mill.) is an economically important crop in many countries, including India. The fruit is rich in lycopene, which has beneficial health effects. About 150 million tons of tomatoes were produced in the world in 2009. China, the largest producer, accounted for about one quarter of the global output, followed by United States and India. For one variety, plum or processing tomatoes, California accounts for $90 \%$ of U.S. production and $35 \%$ of world production. They contain the carotene lycopene, one of the most powerful natural antioxidants.

Tomato is being affected by many pest and viral disease. Besides fungal, bacterial and phytoplasmal infections, it is also affected by large number of viral diseases. Of all the diseases reported in tomato, tomato leaf curl virus 
(ToLCV), a geminivirus (Geminiviridae: subgroup - III) is the most important and destructive viral pathogen in many parts of India (Pratap et al., 2011).

While the use of disease resistant cultivars may present an effective way of controlling the above diseases, genetic engineering techniques continue to play a major role in the development of disease resistant cultivars. Various factors that affect the development of techniques for the isolation and identification of many genes involved in plant disease resistance, morphology and development have been studied. In addition, different factors such as Agrobacterium cell density (Murray et al., 1998), regeneration and co-cultivation conditions ( $\mathrm{Hu}$ and Phillips, 2001), addition of acetosyringone and cell competence after wounding (Murray et al., 1998) and gene constructs (Krasnyanski et al., 2001) were found to play a major role in tomato transformation. The first report of tomato transformation was forwarded by (McCormick et al., 1986) and since then, there have been numerous publications on transformation of various tomato cultivars (Saker et al., 2008). Standardization of tomato transformation procedures are, still, incomplete as different tomato cultivars vary in their response to specific treatment. The present study was undertaken to develop an efficient procedure for the production of viral resistant-transgenic tomato plants expressing coat protein $(\mathrm{CP})$ gene of ToLCV.

\section{Materials and methods}

Agrobacterium-mediated tomato transformation was performed with some modifications. All culture media used in the transformation and regeneration experiments were solidified with $8 \mathrm{~g} / \mathrm{L}$ agar and its $\mathrm{pH}$ was adjusted to 5.7 .

\section{Isolation and culture of embryo from tomato seed}

Embryo isolation is initiated by surface sterilization of the seed by washing in water containing few drops of tween-20 solution for 15 min with intermittent shaking under sterile conditions followed by rigorous washing of seeds with double distilled water and with $70 \%$ ethanol for $90 \mathrm{sec}$ and with $0.1 \%$ mercuric chloride solution for about $10 \mathrm{~min}$. The seeds were then washed 3 times with double distilled water for 1, 3 and $5 \mathrm{~min}$. The seeds were soaked in sterile distilled water, overnight for embryo isolation. Embryo isolation was continued in a sterile LAF by making a cut on the sharper end of the seed.
Blunt side of seed was gently pressed by the blunt end of scalpel and the embryo was squeezed out. The isolated embryos were inoculated on MS basal medium and kept in a growth room that was exposed to $16 \mathrm{hrs}$ light and 8 hrs dark period at $25^{\circ} \mathrm{C}$. The seeds were also kept for germination without embryo isolation on MS basal medium and on wet filter paper. The plates and bottles were kept in a sterile room at $25^{\circ} \mathrm{C}$.

\section{Agrobacterium culture and OD selection}

A coat protein (antiviral CP gene from ToLCV) gene cloned in Agrobacterium tumefaciens LBA4404 (harboring plasmid pGPTV-kan) strain was used. Optimization of Agrobacterium concentration for gene transfer requires its culture which was done by inoculating with $1 \mathrm{ml}$ of culture broth overnight grown culture of Agrobacterium LBA4404 into 11 tubes containing $10 \mathrm{ml}$ of LB medium with streptomycin, kanamycin and rifampicin $(10 \mu \mathrm{l}$ each of $50 \mathrm{mg} / \mathrm{ml}$ concentration). All tubes were kept for incubation at $28^{\circ} \mathrm{C}$ on a rotary shaker and OD was taken at $600 \mathrm{~nm}$ after each and every one hour to get a defined concentration of culture using UV spectrophotometer. Tubes having OD- 0.6, 0.7, 0.8, and 0.9 was stored at $20^{\circ} \mathrm{C}$ for further use. At $-20^{\circ} \mathrm{C}$ all the metabolic activities of the bacterial cells get ceased. These cultures can be used to infect the explants (Zheng et al., 2004).

\section{Transformation and regeneration protocol}

Pretreatment is a process of preparation of explants for the agroinfection or co-cultivation. The explants should be healthy and large enough of size to sustain the transformation. Pretreatment of the explant was done by cutting the leaves of one week old embryo germinated tomato plants on the margin using a sterile scalpel to get the leaf disc of about $0.4 \mathrm{~cm} \times 0.4 \mathrm{~cm}$ followed by cotyledon $(1 \mathrm{~cm})$.Old grown callus of tomato were cut into small pieces by using a sharp, sterile scalpel. All the leaf disc were placed in the regeneration medium (MSRT, MS salts and vitamins, $30 \mathrm{~g} / \mathrm{L}$ sucrose, $2.5 \mathrm{mg} / \mathrm{L}$ BAP and $0.1 \mathrm{mg} / \mathrm{L}$ IAA), with axial position downward and incubated under condition of light in the growth room for 2 days at $25^{\circ} \mathrm{C}$. Stem and callus were also placed in the regeneration medium (MS-RT) at $25^{\circ} \mathrm{C}$ for 2 days. Co-cultivation of tomato explants with Agrobacterium LBA4404 were done by using two different solutions; one with $5 \%$ sucrose solution and other with MS-basal (medium with macroelements, microelements, iron, vitamins, amino acids, and sucrose) 
liquid medium. Co-cultivation of explants with Agrobacterium LBA4404 using 5\% sucrose solution and MS-Basal medium was done by using Agrobacterium tumefaciens (LBA4404) culture of different OD (0.5 to $0.9)$ at $600 \mathrm{~nm}$. The culture was transferred to $2 \mathrm{ml}$ Eppendorf tubes and centrifuged at 6000rpm for 8 to 10 min to obtain the cell pellets and the pellets were dissolved in $10 \mathrm{ml} 5 \%$ sucrose solution/MS-Basal liquid medium. Culture of five different OD was dissolved separately in sucrose solution/MS-Basal medium. Solution was vortexed and kept at room temperature followed by the inoculation of the pretreated explants. Pretreated explants were inoculated into the sucrose solution/MS-Basal liquid medium of Agrobacterium LBA4404 (harboring the plasmid pGPTV-kan with Cp gene) of different OD $(0.5,0.6,0.7,0.8,0.9)$ After incubation the sucrose solution containing explants were swirled gently for about $10 \mathrm{~min}$ and were transferred to the blotting paper by using sterile forceps. Explants were dried carefully for about $10 \mathrm{~min}$ and were placed onto MS-RT medium (MS-RT, MS salts and vitamins, $30 \mathrm{~g} / \mathrm{L}$ sucrose, $2.5 \mathrm{mg} / \mathrm{L}$ BAP and $0.1 \mathrm{mg} / \mathrm{L}$ IAA). The PTC bottles were kept at $28^{\circ} \mathrm{C}$ in dark condition for two days.

The procedure used for the selection media transfer was standardized by using different concentrations of antibiotics and based on trial and error method. MSRT media was melted, cooled to $45^{\circ} \mathrm{C}$ and $100 \mu \mathrm{l}$ of antibiotics namely augmentin, cefotaxime $(250 \mathrm{mg} / \mathrm{ml})$ and kanamycin $(50 \mathrm{mg} / \mathrm{ml})$ were added into the $30 \mathrm{ml}$ of media. Antibiotic containing water solutions was prepared by adding $100 \mu \mathrm{l}$ of augmenting $(250 \mathrm{mg} / \mathrm{ml})$ into $30 \mathrm{ml}$ of distilled water. The explants were washed with $0.2 \%$ sodium hypochlorite solution for 3 min followed by washing with augmentin solution, 2 times for $5 \mathrm{~min}$ followed by washing with double distilled water, 3 times for $5 \mathrm{~min}$ with continuous swirling. After washing with distilled water, explants were washed with MS-liquid medium for twice and kept for drying on a sterile filter paper. When the explants are fully dried, the leaf discs, stem and callus were kept on selection medium (containing antibiotics, namely Augmentin, cefotaxime $(250 \mathrm{mg} / \mathrm{ml})$ and kanamycin $(50 \mathrm{mg} / \mathrm{ml})$ by using sterile forceps and kept for incubation at $26^{\circ} \mathrm{C}$ under light condition. Kanamycin-resistant calli obtained after a second round of selection were transferred to a fresh selection medium. Once in every two weeks, the fresh and healthy looking kanamycin-resistant calli were sub-cultured in a fresh selection medium for shoot regeneration (Tahmasebi et al., 2012).
After approximately 6-8 weeks, shoots were excised and transferred to shoot elongation medium (MS salts and vitamins, $30 \mathrm{~g} / \mathrm{L}$ sucrose, $1 \mathrm{mg} / \mathrm{L}$ BAP, $0.1 \mathrm{mg} / \mathrm{L}$ IAA and $250 \mathrm{mg} / \mathrm{L}$ cefotaxime) for shoot development. The shoots obtained were transferred to rooting medium (MS salts and vitamins, $30 \mathrm{~g} / \mathrm{L}$ sucrose, $1 \mathrm{mg} / \mathrm{L}$ IAA and $250 \mathrm{mg} / \mathrm{L}$ cefotaxime) for root development. A set of explants which were not co-cultivated with Agrobacterium were also regenerated, as described above, as a negative control. Transformation frequency was expressed as a percentage of the number of shoots recovered from kanamycin-resistant calli relative to the total number of incubated kanamycin-resistant calli. Any rooting shoot on the selection medium containing 25 $\mathrm{mg} / \mathrm{L}$ kanamycin was considered as a transformant. (Sharma et al., 2009).

\section{Effect of Agrobacterium culture density}

Bacterial densities (OD600) ranging from 0.5 to 0.9 were tested to determine the optimum density for transformation.

\section{Effect of Sucrose solution and MS liquid medium for co-cultivation}

Sucrose solution (10\%) and MS-Basal liquid medium were tested to determine the optimum medium for transformation.

\section{Molecular verification of the transformant}

To confirm the presence of the $\mathrm{CP}$ gene in the regenerated transformed plants, total DNAs were isolated from both transformed and non transformed (negative control) plant samples and were used as templates for PCR. Plasmid DNA was also isolated and used as a positive control.

\section{Rapid plant DNA extraction}

Rapid plant DNA extraction was carried out following CTAB (cetyl trimethyl ammonium bromide) protocol, which is a modification of the method of Doyle and Doyle (1987).

\section{Polymerase Chain Reaction (PCR)}

The presence of $\mathrm{CP}$ gene was investigated by PCR amplification. Specific oligonucleotide primers for $\mathrm{CP}$ gene were 'forward': 5-ATGGCGAAGCGACCAG-3 
and 'reverse': 5-TTAATTTGTGACCGAATCAT-3. CP gene is of $771 \mathrm{bp}$ or $\approx 800 \mathrm{bp}$. Amplified DNA fragments were electrophoresed on $1.0 \%$ agarose gel and detected by ethidium bromide staining and photographed under Gel Doc.The presence of the target band in the transformants and its absence in the untransformed plants is considered as a proof of successful transformation (Tumer et al., 1987; Fuchs et al., 1996).

\section{Results and discussion}

A protocol for transformation and regeneration of tomato plants has been developed on the basis of the results of the optimization experiments conducted in the present study.

\section{Embryogenesis}

Isolated embryo from the tomato seeds were partially grown into cotyledons after 7 days and fully grown after 15 days of incubation (Fig. 1, A). Surface sterilized seeds were grown on wet filter paper into cotyledons after one week (Fig. 1, B). Overnight water soaked seeds were neither grown on MS- Basal media nor on the wet filter paper (Fig. 1, C, D).

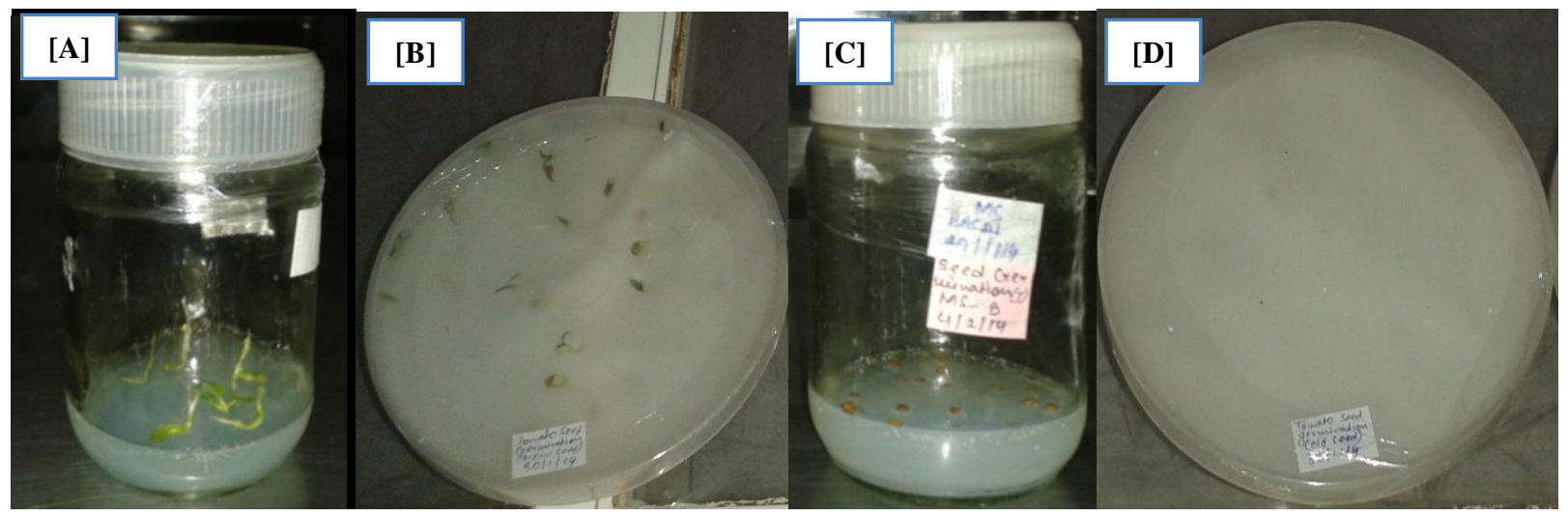

Fig. 1: Explant culture. (A) Regenerated cotyledons from embryo (B) Germinated sterile seeds on wet filter paper (C) Non-germinated overnight soaked seeds on MS-basal medium (D) Non-germinated overnight soaked seeds on wet filter paper.

\section{Agrobacterium culture}

Agrobacterium LBA4404 (containing plasmid pGPTVkan with CP gene) used for desired gene transfer was grown into LB medium and specific OD (OD- 0.5, 0.6, $0.7,0.8,0.9$,) was selected. Time of incubation and growth of cells were plotted (X and $\mathrm{Y}$ ) that shows the lag and log phase of growth (Fig. 2).

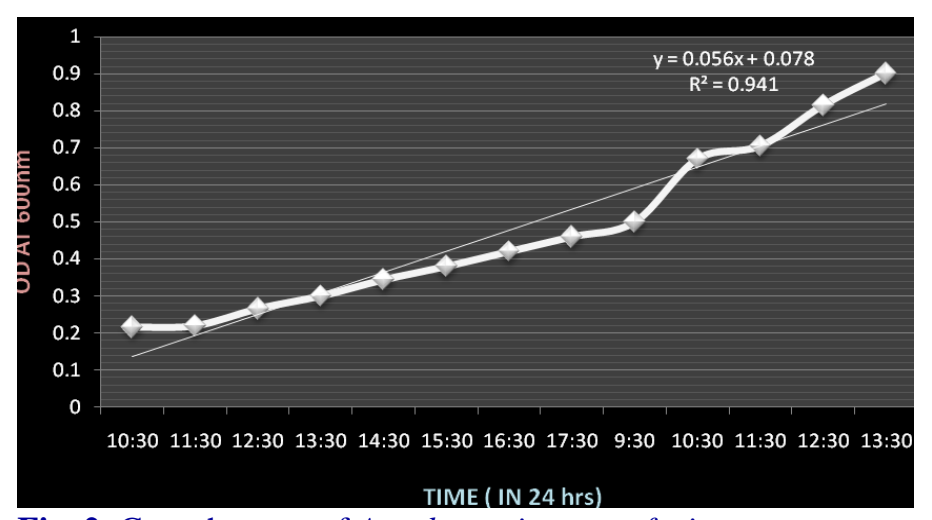

Fig. 2: Growth curve of Agrobacterium tumefaciens.

\section{Pretreatment, co-cultivation and selection media transfer}

Cotyledon and leaf explants of 15 days old seedlings from the embryo generated plantlet were cut and incubated on MS-RT medium for two days. Pretreatment allows the explants to get adapted on the artificial media. Fig. 3 (A) shows the pretreatment of explants.

In co-cultivation of explants, 5\% sucrose with Agrobacterium cells and MS-liquid media with bacteria were used to infect the plant cells. At this point, the bacterial cells attach to the plant tissue for further infection. After a 10min incubation with the bacterial solution the explants were incubated on the MS-RT medium in dark for 2 days. Bacterial cells activate their vir genes for gene transfer and the gene of interest can be transferred into plant cells within these two days Fig. 3 (B) shows the co-cultivation flask. Fig. 3 (C) and (D) shows selection media transfer. Co-cultivation of 
explants using MS-liquid medium showed more efficiency of transformation than that of $5 \%$ sucrose (Beachy et al., 1990; Murashige and Skoog, 1962; Dellaporta et al., 1983).

After two days of co-cultivation the explants were transferred to a selection medium containing antibiotics (Augmentin, Cefatoxime, and kanamycin). Out of 102 explants only 53 survived. Kanamycin kills the nontransformed plant cells, while transformed cells express the kanamycin resistant marker gene and stays alive.
Cefatoxime kills the Agrobacterium cells present on the plant cells and Augmentin inhibits the growth of other microbes. Sub culturing of regenerated plantlet was done after the survival of explants on selection media (Spena et al., 1992; Pilowsky and Cohen, 1990).

Fig. 3 (E) and (F) clearly shows the difference between control plant and transformed plant. Transformed explants were grown into plantlets while control explants (without the desired gene) died because of susceptibility to kanamycin.
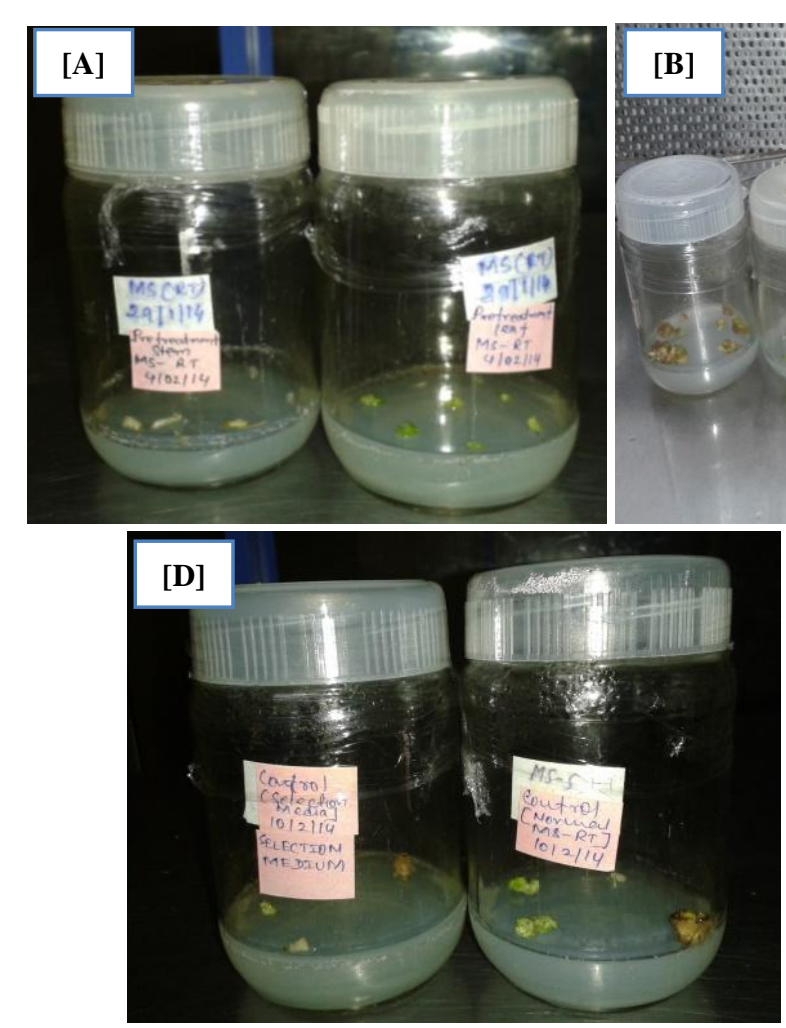
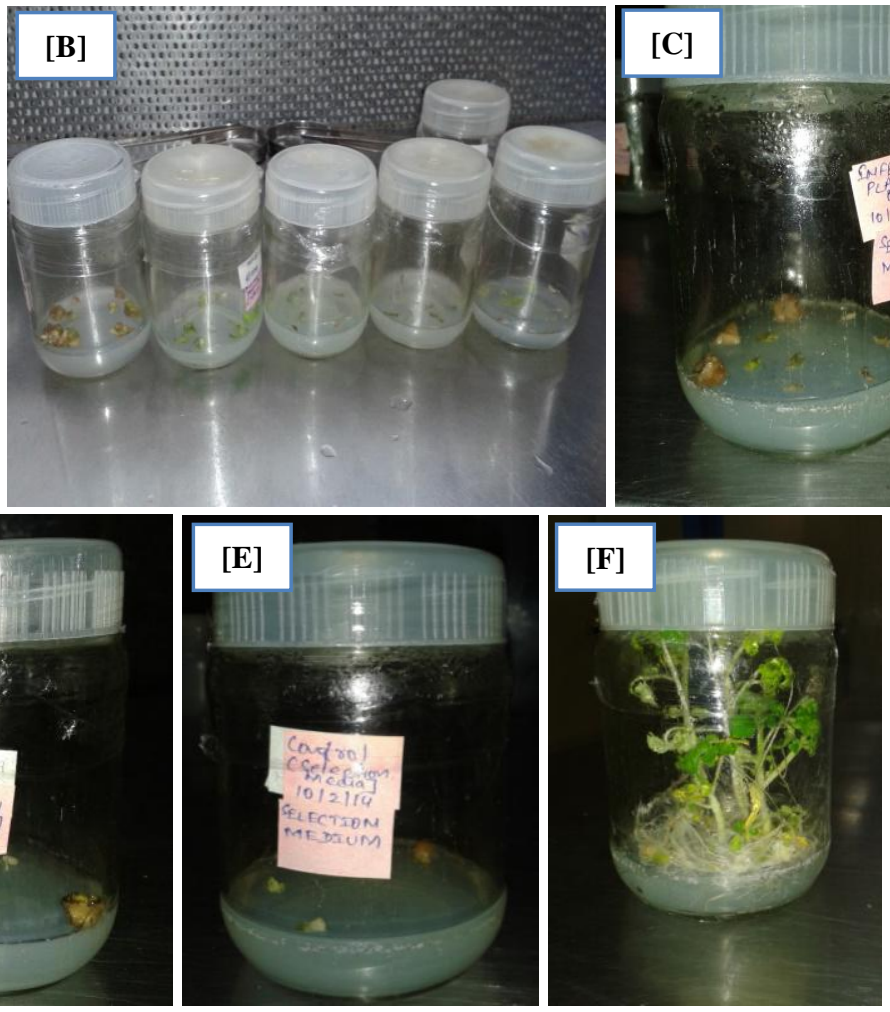

Fig. 3: Pretreatment, co-cultivation, Selection media transfer and regeneration of transgenic plant. (A) Pretreatment of explant (B) Co-cultivation of explant with different concentration of Agrobacterium culture (C) Transfer of co-cultivated explants on selection media (D) Transfer of control plants on selection mediaand MS-RT medium (E) Control explants on selection medium (F) Fully grown transformed tomato plantlet on selection media. ${ }^{[20]}$

The results of survivals of transformed and non transformed plantlets at various stages are summarized in Table 1. It also signifies the transformation efficiency of the experiment. The frequency of survival of explants on selection media was found to be about $(51.96 \%, 53 / 102)$, which was less than non transformed control explants $(75.0 \%, 75 / 100)$ (Zhuk and Rassokha, 1992).

Direct shoot initiation rather than the callus, was observed at the cut edge of the proximal end. Each explant produced a number of shoots from several trans- formation events. The true shoots were subsequently transferred on fresh selection medium for shoot elongation. About 48.03\%, (49/102) trans-formed shoots survived during shoot elongation and the elongated shoots were placed in a rooting medium. Root development was carried out and the frequency of root development was 15.68\%, (16/102) (Kara et al., 1994).

Table 2 shows the transformation efficiency at different OD of Agrobacterium culture. From the current table it is clear that maximum infectivity and transformation efficiency was achieved from 0.7 OD of culture. 
Table 1. Percentage of transformation and survival of transformed plant.

\begin{tabular}{lllll}
\hline \multirow{2}{*}{ Stage } & \multicolumn{2}{l}{ Co-cultivated } & Control \\
\cline { 2 - 5 } & Survived/Total & Percentage & Survived/Total & Percentage \\
\hline Co-cultivation & $79 / 102$ & 77.45 & $90 / 100$ & 90 \\
Growth on selection media & $53 / 102$ & 51.96 & $75 / 100$ & 75 \\
Shoot elongation & $49 / 102$ & 48.03 & $70 / 100$ & 70 \\
Rooting & $16 / 102$ & 15.68 & $65 / 100$ & 65 \\
\hline
\end{tabular}

Control plants were grown on MS-RT medium without any co-cultivation with Agrobacterium.

Table 2. Transformation efficiency at different OD of Agrobacterium culture.

\begin{tabular}{lll}
\hline Optical density of culture & No of explants transformed & Transformation percentage \\
\hline 0.5 & $5 / 102$ & 4.90 \\
0.6 & $10 / 102$ & 9.80 \\
0.7 & $25 / 102$ & 24.50 \\
0.8 & $9 / 102$ & 8.82 \\
0.9 & $4 / 102$ & 3.92 \\
\hline
\end{tabular}

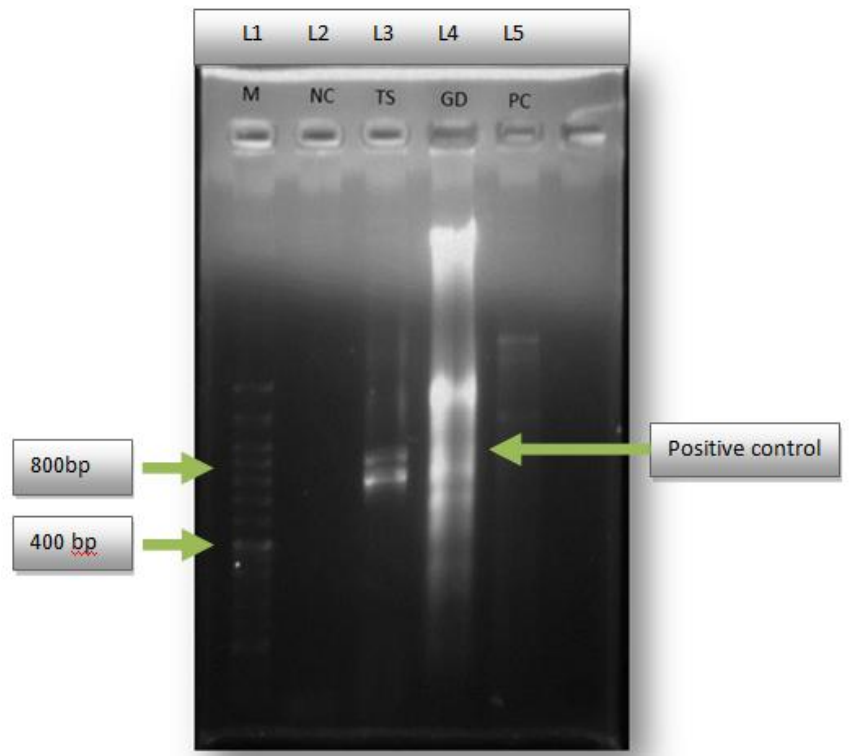

Fig. 4: Gel Electrophoresis of PCR product. Lane1 (L1): 100kb marker, Lane2 (L2): Negative control of PCR, Lane3 (L3): PCR amplified product of transformed plant (Test sample), lane4 (L4): Genomic DNA of tomato, lane 5 (L5): positive control for CP DNA.

\section{Polymerase chain reaction and confirmation of Coat protein (CP) transfer by gel electrophoresis}

Result of polymerase chain reaction followed by gel electrophoresis in Fig. 4 confirms the presence of coat protein in the tomato genome of transformed plant. In the gel electrophoresis, lane 1 contains marker DNA band of $100 \mathrm{bp}$, lane 2 contains negative control for PCR i.e., genomic DNA of control tomato plant, lane 3 contains the amplified PCR product, lane 4 contains the genomic DNA of tomato, and lane 5 contains the positive control for coat protein. PCR amplified product $(\approx 800 \mathrm{bp})$ band matches with positive control $(\approx 800 \mathrm{bp})$ and shows that it is of $800 \mathrm{bp}$. This confirms the amplification of coat protein sequence in the transformed plantlet.

Embryo culture and in-vitro seed germination is very important and major step in plant tissue culture. It provides the plant material being used for transformation experiment. Embryo was grown on MS-Basal medium and gives rise to cotyledons and leaves after 14 days as written on review articles. All overnight water soaked tomato seeds failed to germinate under in-vitro condition. This result was different from the result of review articles and shows human error and seeds potentiality to germinate in-vitro. All surface sterile seeds germinated on wet filter paper and shows that embryo needs only water as an external source for germination. Seed contains endosperm that supplies all the nutrients for germination and growth.

Agrobacterium LBA4404 containing the plasmid pGPTV-kan with Cp gene was cultured in LB medium. LB medium with rifampicin, streptomycin and kanamycin was used to select cells. OD selection was done for determination of highest efficiency of bacterium to transform a plant cell. Results shows that Agrobacterium culture of OD- 0.7 at $600 \mathrm{~nm}$ was most efficient in transformation with an efficiency of $24.50 \%$. This result differs from the review article and may be due to different tomato variety, or different type of explants.

Pretreatment of explants was required for adaptation of explants to the media. Pretreatment was done by incubating the explants on MS-RT media for 2 days. 
Co-cultivation of explants was done using suspension of cells in MS-liquid medium and in 5\% sucrose solution. Co-cultivation allows the bacterial cells to transfer the desired DNA into the plant cells. Plant cell integrates the DNA into the genome randomly and expresses the foreign DNA. Co-cultivation followed by selection media transfer shown that MS-liquid suspension of bacterium is more efficient in transferring the DNA than any other method as described in the review literature.

Selection media transfer, selects the transformed cells on the basis of the presence of marker gene into the genome of transformed explants. The marker gene is kanamycin resistant gene that allows the growth of transformed plantlet onto kanamycin containing medium. A very high percentage of cell survival had been reported by standardizing the procedure of transfer of co-cultivated explants onto selection medium. Transformation efficiency was found to be higher when compared with review article and shown that the standardized protocol as a better option for transformation of tomato plant.

In order to confirm the gene transfer in our study, PCR was done using the transformed tissue DNA and CP specific primers. The Gel electrophoresis confirms the presence of CP DNA in the tomato plant. Many review articles have shown that the transformed plant are resistant to the virus under greenhouse condition but large no of field trail is required for the confirmation of resistance towards the Tomato leaf curl virus.

\section{Summary and conclusion}

Tomato leaf curl virus disease is a devastating disease of tomato varieties in India. Efforts have been made to develop disease-resistant varieties of tomato by conventional breeding, but none has been able to produce a potent virus-resistant variety against the disease. However, several researchers have attempted Agrobacterium mediated genetic transformation to produce transgenic tomato plants expressing the $\mathrm{CP}$ gene of ToLCV.

Moreover, our efforts in this direction are a preliminary process to achieve highest transformation efficiency through a modified protocol. The protocols have been developed for transferring a foreign gene into the tomato plant that has a wide scope in generation of transgenic plants using other genes of interest.

The prime area of interest after our study is detecting the position effect of transferred gene into the tomato plant. Agrobacterium method of transformation follows random integration of transgene into the genome. Integration into a functional gene disrupts the normal plant physiology. So considerable efforts have to be made, to eradicate the problem of position effect.

\section{Conflict of interest statement}

Authors declare that they have no conflict of interest.

\section{References}

Beachy, R. N., Loesch-Frie, S., Tumer, N. E., 1990. Coat protein mediated resistance against virus infection. Annu. Rev. Phytopathol. 28, 451-474.

Dellaporta, S. J., Wood, J., Hicks, J. B., 1983. A plant DNA mini preparation. Version II. Plant Mol. Biol. Rep. 1(4), 19-21.

Doyle, J.J., Doyle, J.L., 1987. A rapid DNA isolation procedure for small quantities of fresh leaf tissue. Phytochem. Bull. 19, 11-15.

Fuchs, M., Provvidenti, R., Slighton, J. L., Gonsalves, D., 1996. Evaluation of transgenic tomato plants expressing the coat protein gene of cucumber mosaic virus strain WL under field conditions. Plant Dis. 80, 270-275.

Hu, W., Phillips, G. C., 2001. A combination of over growth-control antibiotics improves Agrobacterium tumefaciens mediated transformation efficiency for cultivated tomato (L. esculentum). In Vitro Cell. Develop. Biol. Plant. 37, 12-18.

Kara, D. W., Reavy, B., Barker, H., 1994. An Introduction to Agrobacterium tumefaciens Mediated Transformation Techniques (A Handbook of Methods Used in the Virology Department). In: SCRI Transformation Techniques, Version 1.1, 7.

Krasnyanski, S. F., Sandhu, J., Domier, L. L., Buetow, D. E., Korban, S. S., 2001. Effect of an enhanced CaMV 35S promoter and a fruit-specific promoter on uida gene expression in transgenic tomato plants. In Vitro Cell. Develop. Biol. Plant. 1, 427-433.

McCormick, S., Niedermeyer, J., Fry, J., Barnason, A., Horsch, R., Fraley, R., 1986. Leaf disc transformation of cultivated tomato (L. esculentum) using Agrobacterium tumefaciens. Plant Cell Rep. 5(2), 81-84.

Murashige, T., Skoog, F., 1962. A revised medium for rapid growth and bioassays with tobacco tissue cultures. Physiol. Plant.15, 473-497. 
Murray, S.L., Vuuren, R.J., Berger, D. K., Van-Vuuren, R.J., 1998, Tomato transformation is influenced by acetosyringone and Agrobacterium tumefaciens cell density. J. S. Afr. Soc. Hortic. Sci. 8, 60-64.

Pilowsky, M., Cohen, S., 1990. Tolerance to tomato yellow leaf curl virus derived from Lycopersicon peruvianum. Plant Dis. 74, 248-250.

Pratap, D., Kashikar, A. R., Mukherjee, S. K., 2011. Molecular characterization and infectivity of a Tomato leaf curl New Delhi virus variant associated with newly emerging yellow mosaic disease of eggplant in India. Virol. J. 8, 305.

Saker, M.M., Hussein, H.A., Osman, N. H., Soliman, M. H., 2008. In vitro production of transgenic tomatoes expressing defensin gene using newly developed regeneration and transformation system. Arab. J. Biotechnol. 11(1), 59-70.

Sharma, M.K., Solanke, A.U., Jani, D., Singh, Y., Sharma, A. K., 2009. A simple and efficient Agrobacteriummediated procedure for transformation of tomato. J. Biosci. 34, 423.

Spena, A., Esttruch, J.J., Prinsen, E., Nacken, W., Vanonckelen, H., Sommer, H., 1992.Anther-specific expression of the rolB gene of Agrobacterium rhizogenes increases IAA content in anthers and alters anther development and whole flower growth. Theor. Appl. Genet. 84, 520-527.

Tahmasebi, A., Aram, F., Ebrahimi, M., MohammadiDehcheshmeh, M., Ebrahimie, E., 2012. Genomewide analysis of cytosolic and chloroplastic isoforms of glutathione reductase in plant cells. Plant Omics 5(2), 94-102.

Tumer, N. E., O'Connell, K. M., Nelson, R. S., Sanders, P. R., Beachy, R. N., Fraley, R. T., Shah, D. M., 1987. Expression of alfalfa mosaic virus coat protein gene confers cross-protection in transgenic tobacco and tomato plants. EMBO J. 6(5), 1181-1188.

Zheng, SJ., Henken, B., Kyun Ahn, Y., Krens, F. A., Kik, C., 2004. The development of a reproducible Agrobacterium tumefaciens transformation system for garlic (Allium sativum L.) and the production of transgenic garlic resistant to beet armyworm (Spodoptera exigua Hübner). Mol. Breed. 14(3), 293-307.

Zhuk, I. P., Rassokha, S. N., 1992. Regeneration and selection of somatic clones of tomato for resistance to TMV. Rossiiskoi Akad. Sel'skokhozyaistvennykh Nauk. 11/12, 18-21.

\section{How to cite this article:}

Mishra, P. K., Jai Shanker Pillai, H. P., Kopa, H., Gupta, M., Arjunan, S., 2017. A modified protocol for Agrobacterium mediated transformation of tomato plants. Int. J. Curr. Res. Biosci. Plant Biol. 4(1), 123-130. doi: http://dx.doi.org/10.20546/ijcrbp.2017.401.016 